\title{
Pathogens in Surface Water in Jos and Environs, Plateau State, Nigeria
}

\author{
V.A.Pam, D.A.Daku, A,Akut,K. Hassan, , K.I.Ogbu, S.I.Bata, A.Obalisa \\ ${ }^{1}$ Department of Parasitology,FCAH AND PT,NVRI,Vom \\ 2Department of Zoology University of Jos \\ ${ }^{3}$ Deparment of Animal Health, FCAH AND PT,NVRI,Vom \\ ${ }^{4}$ Deparment of Extension, FCAH AND PT,NVRI,Vom \\ ${ }^{5}$ College of Act and Science, Plateau State.
}

\begin{abstract}
This study investigated the epidemiology of Cryptosporidium in Jos North and South Local Government Areas of Plateau State, Nigeria as from January-December 2007. Water were collected from some of the areas visited, samples were taken to the parasitology and diagnosis laboratory of the National Veterinary Research Institute, Vom for analysis. Cryptosporidium species and other parasites were determined by parasitological techniques (Formol-ether concentration techniques while Staining was done using Zielh Neelsen Technique). The occurrence of Cryptosporidium specie in water samples revealed higher prevalence rates at the peak of the rainy season in July, August and September having means of 26.2, 22.9 and 19.7 respectively while the least mean was recorded in the dry season in the months of January, February and March as follows: 4.1, 6.1 and 5.5. These results are discussed in relation to the epidemiology, distribution and significance of Cryptosporidium in the study area and possible recommendations given.
\end{abstract}

\section{Keywords: - Cryptosporidium species, Epidemiology, Jos, Plateau State, Water}

\section{INTRODUCTION}

Cryptosporidium species have recently been recognized as a worldwide cause of diarrhoea in all age groups, yet its major impact has been among individuals with weaken immune systems (including people with human immunodefieciency syndrome or Acquired Immunodefiency Syndrome) and transplant recipients. In such people, this diarrhoeal infection is not just bothersome but can lead to severe and potentially life threatening wasting and malnutrition [1], [2]. During the large drinking water related outbreak in Milwaukee the mean incubation period was estimated to range from 3 to 7 days. A study of emergency room admissions of elderly people during the Milwaukee outbreak suggests an incubation period of 5 to 6 days based on measurements of when the water was turbid[3], [4], which is lower than that seen for children (7 days) and adults (8 days)[5], [6]. An estimation of incubation periods for a swimming pool outbreak suggested people were ill 5 days after exposure [7]. In a large waterborne outbreak in Japan there were 14 people who had a time limited exposure to the contaminated drinking water and the mean incubation period was 6.4 days (range 5 to 8 ). A restaurant outbreak in Spokane, Washington resulted in incubation periods of between 3 and 9 days [8], [9]. In an outbreak linked to apple cider the incubation period was 6 days (range, 10 hours to 13 days). An outbreak of cryptosporidiosis in HIV positive patients through contaminated ice found a longer incubation period of 13 days compared to that previously reported for people without an immunodeficiency [10].There is clearly quite a degree of variation in the time from exposure to symptoms amongst patients in an outbreak. While some of this variation probably results from inaccuracies in the estimation of exposure events and symptom on set there also appears to be genuine differences in the time required to get symptoms. There is a possibility that prior infection might alter the incubation period and the inoculums size might similarly influence the incubation period, although evidence for this is sparse. The extent to which the incubation period varies between different species of Cryptosporidium remains unclear.

Cryptosporidium species remains a risk to drinking water consumers, Runoff from animal production have been a concern for decades due to the environmental risk of sources of water contamination. Runoff from these facilities may contain high amounts of nutrients, solid, and microorganisms that have the potential of degrading surface water [11], [12]. This is of great concern when there is a substantial risk for disease transmission by water -borne microorganisms especially pathogens and Cryptosporidium species is one of such pathogens. This protozoa parasite which is excreted in the form of an oocyst may be found in large quantities in the faeces of diseased livestock, both open range and those in concentrated animal houses, have been associated with high concentrations of Cryptosporidium species[13], 14].

The first published drinking water related outbreaks of cryptosporidiosis were linked to a sewage contaminated well supplying a community in Texas[15], [14] and a contaminated surface water source in Georgia, 
USA,[16].Evidence from outbreaks varies and can be categorized using an algorithm[14]. This categorization is a relatively crude device and there is always some doubt about whether an outbreak was really caused by drinking water especially in the absence of a well-executed case-control study.

In England and Wales there were large drinking water borne outbreaks in 1989 and 1990 that led to the establishment of an Expert Group under the chairmanship of Sir John Badenoch and subsequently by Professor Ian Bouchier. The three expert reports [17], [3] identified a number of problems with contamination of drinking water supplies, water supply management risk factors and how to prevent outbreaks due to public water supplies. Their recommendations remain very relevant today and have had major influences in how water companies design and operate their water treatment.

Although drinking water outbreaks accounted for only around $8 \%$ of Cryptosporidium cases, the role of public water supplies in the majority of cases is unclear. However, a strong correlation between rainfall and nontravel related a case of cryptosporidiosis in springtime implies that many cases could have been related to water supplies lacking sufficiently robust water treatment [18], [19]. Since the change in regulations there has been a substantial reduction in cryptosporidiosis in the spring that is linked to improved water treatment [16].

There have been 15 drinking water related Cryptosporidium outbreaks in the US between 1991 and 2002 [20] and 55 in the UK. The reason why the UK has had so many outbreaks relative to other countries is thought to be partly due to good laboratory and disease surveillance infrastructure. Where the organism is looked for in a systematic way in diarrheal patients and reported through surveillance outbreaks often appear. There is an implied assumption that drinking water related outbreaks are common in other countries but remain undetected.

\section{MATERIALS AND METHODS}

The study was carried out in two Local Government Areas of Plateau State, namely the Jos North Local Government Areas (JNLGA) and Jos South Local Government Areas (JSLGA) Government Areas.

\subsection{Water Collection}

Water samples were collected from five different sites visited (Yanshanu, Abattior, Farin gadan, Kasuwa Doki, and Gada-Biu). At each sampling site fifty samples were collected, a total of two hundred and fifty water samples were collected in all the sites visited. One liter of water was randomly collected at different points at depth of about $1.5 \mathrm{~m}$ per week from the respective water bodies in plastic containers and transported to the laboratory. Sampling was carried out for a period of 12 months (from January to December, 2011).

\section{FILTRATION}

Water samples were filtered as soon as they arrived the laboratory. The samples were passed through a $60 \mathrm{~mm}$ and $90 \mathrm{~mm}$ mesh to remove debris. It was then filtered using another filter (mesh size $400-450 \mu \mathrm{m}$ ) into the filter flask.

i. Filters were rewashed several times using $200 \mathrm{ml}$ of distilled water in which $10 \%$ wash solution concentration (prepared using tween 20 and distilled water had been incorporated so as to enhance the recovery of oocysts concentration [21].

ii. Sodium Chloride Floatation technique was used for the concentration of oocysts, after the back washing.

\section{MICROSCOPIC EXAMINATION}

Demonstration of Cryptosporidium oocysts was done by microscopic examination of smears made after the concentration of water samples, fixed with $70 \%$ methanol and stained using the modified ZiehlNeelsen staining technique [22], [23].

\section{RESULTS}

Figure 1 below shows the monthly mean occurrence of Cryptosporidium species in water. There were differences between the seasonal distribution of Cryptosporidium species, highest contaminations was found during the months of July (26.2) August (22.9) and September (19.7), slightly lower at the early part of the rainy season during the months of May (9.4) and June (10.2). The infection was found to be less during the early dry season (October, November, and December) (figure 1). 


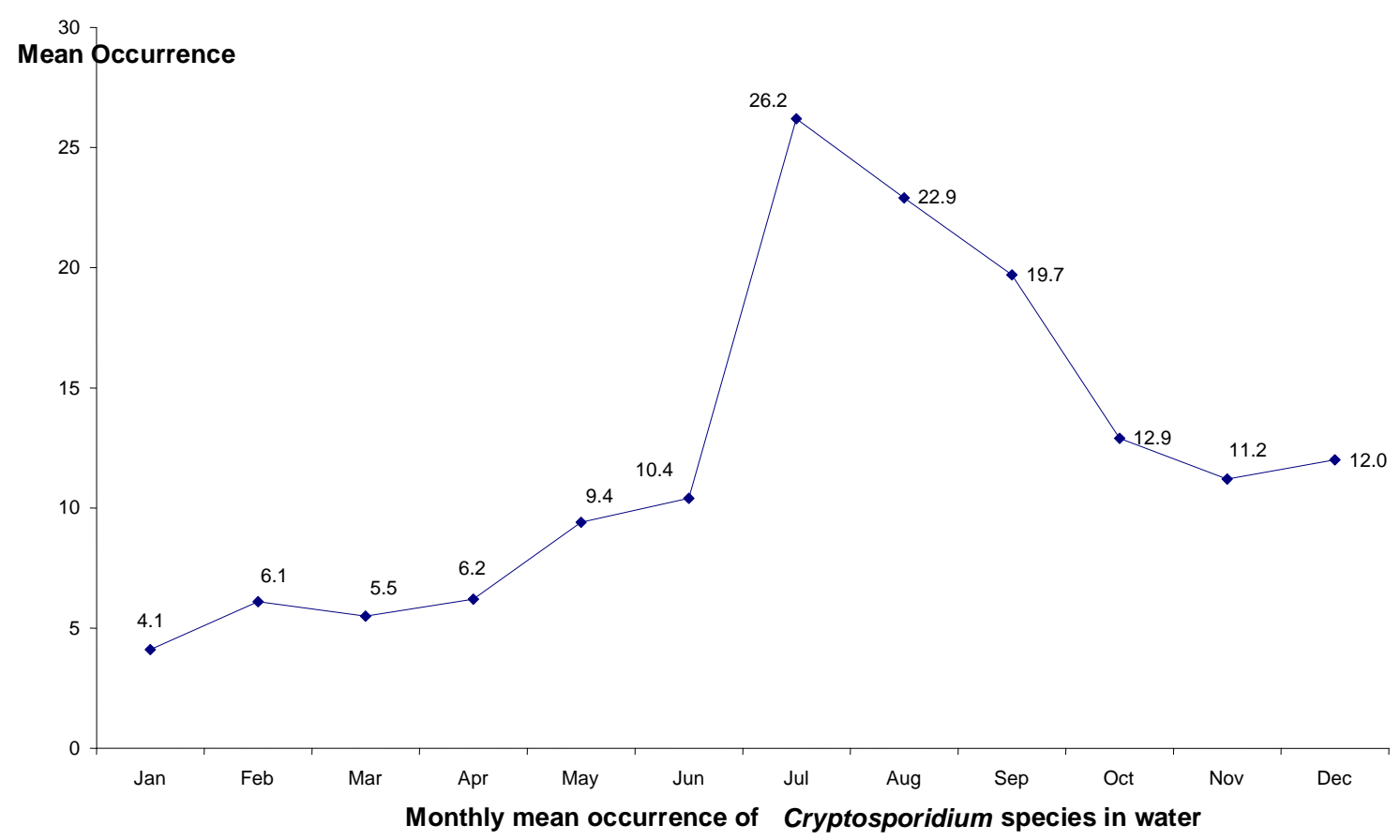

Figure 1: The Mean Occurrence of Cryptosporidium species in water

\section{DISCUSSION}

We attempted to characterize seasonal variation in the incidence of Cryptosporidium species, it was found to occur primarily between January to March which are the dry months with mean occurrence 19.2,13.4 and 12.6 respectively and two months into the rains April and May,with means of 10.6 and 9.6, the lower incidence was noticed in the months of September to December with the following means reported respectively 3.6,2.4,2.2, and 2.0. Similar to our finding, [24] reported the incidence of Cryptosporidium species to occur primarily between March and April(2.1-2.8) and between July and September (2.9-4.3\%). In an earlier report, [25] noted significant variations between dry and wet season. Although they looked at the prevalence only in November for the dry season, and May for the wet season, their results suggest that there is a seasonal variation in the prevalence. This could be attributed to the accumulation of oocysts in the soil as a result of continued indiscriminate defecation by both infected animals and humans. The dry season influence the hibernation of oocysts within the areas of endermicity, rains could wash off the oocysts from the soil draining into water channels thereby reducing their concentration in the soil [26], [27], [28], [29], [30], [31]. On the contrary In Guinea Bissau, Cryptosporidium sp. had a prevalence of $7.7 \%$ and was the second most common parasite with a marked seasonal variation, with peak prevalence found consistently at the beginning of or just before the rainy seasons, i.e., from May to July [32]. Furthermore seasonality peaks of cryptosporidiosis have been reported in all regions of Africa,and,with Kenya [33] and Zambia [34] as notable exceptions, peaks tends to occur in the wet months.

The abundance of Cryptosporidium oocysts in water samples in all the twelve months of sampling confirms the endemicity of cryptosporidiosis in the study area. The highest incidence was in the month of July (26.2) followed by August (22.9) and the least was in the month of December (12.0). High pressure and the availability of water to flush the human and animals faeces carrying the oocysts from the surface into the streams or larger water bodies can result to this [35]. On a similarly note, [36] observed that millions of oocysts were execreted by an individual (approximately $10^{6} / \mathrm{ml}$ of stool per day) during an acute stage of the infection and that patient with AIDS had been known to excrete approximately $10^{10}$ oocysts per day, The flow of rains during the rainy season may wash this massive number of oocysts during the rainy season hence, the high concentration of oocysts at such period. This observation is of public health significance, [37], [38], [39], [40], hence oocysts contamination should not be taken lightly. At the peak of the rains, oocysts are dispersed and washed into the various water bodies. This confirms the work of [41] and [19] in Washington State where they found Cryptosporidium oocysts in 34 of 35 samples (97.14\%) ranging from about 0.2 to $65 \%$ oocysts per liter in rainy season. Furthermore [42] reported 49 drinking water related outbreaks due to Cryptosporidium in North America, the UK, and Japan .On a similar note[43] in Taiwa reported $72.20 \%$ frequency of occurrence of Cryptosporidiumoocysts in surface water. Higher prevalence of $(87.1 \%)$ was reported in Canada with densities of $0.07-484$ oocysts per liter[44]. Runoff from dairy farms, drainage from abattoir, and other sources were suspected. Rainfall and runoff events are major factors affecting the presence of total microbial load, including 
Cryptosporidium species, in surface waters and drinking water reservoirs [45], [46]. Cryptosporidium species have emerge as waterborne pathogens of concern, the risk assessment for adverse human effects arising from the presences of oocysts indicates the possibility of water transmission of Cryptosporidium species and other enteric pathogens infection if not adequately treated [42], [47], [46]. When rivers, lakes, and marine environments are used for recreation, contamination from uncontrollable animal and human sources add to the faecal burden.Oocysts concentration were highest when they are influenced by post rainfall run-off and showing decrease through the summer months and oocysts were continuously prevalent in virtually all surface waters. This evidence of a relationship between water-borne oocysts and the overall prevalence of infection with Cryptosporidium in water around the study area needs to be confirmed in other geographic locations, and it indicates the need for further work on understanding the sources of oocysts in urban water sources and the reasons for variability in the intensity of water-borne contamination. Importantly, for waterborne and food borne zoonosis, Veterinarians have significant roles to play.

\section{REFERENCES}

[1] Aboytes, R., DiGiovanni, G.D., Abrams, F.A. and LeChevallier, M.W. (2005). Detection of infectious Cryptosporidium in filtered drinking water. JAWWA 96: 88-98.

[2] American Academy of Pediatrics. (2006). Prevention of illnesses associated with recreational water use. In: Pickering, L.K., Baker, C.J., Long, S.S. and McMillan, J.A., eds. (2006). Red Book: report of the committee on infectious diseases. Elk Grove $27^{\text {th }}$ ed,PP.156-159

[3] Atwill, E.R., Hoar, B., das Gracas Cabral Pereira, M., Tate, K.W., Rulofson, F. and Nader, G. (2003). Improved quantitative estimates of low environmental loading and sporadic periparturient shedding of Cryptosporidiumparvum in adult beef cattle. Applied Environmental Microbiology69: 4604-4610.

[4] Ayeni, A.O., Olubunmi, P.A. and Abe, J.O (1985). The occurrence and effect of Cryptosporidium species in livestock in Ile Ife.Tropical Veterinarian 3: $96-100$.

[5] Angus, K.W., (1988). Mammalian cryptosporidiosis a veterinary perspective.Proceedings of the first international workshop, Edinburgh.Modern Research Institute, June $3^{\text {rd }}-6^{\text {th }} 1988$.

[6] Arrowood, M.J. and Storling, C.R. (1989). Comparison of conventional staining methods and monoclonal antibody-based methods for Cryptosporidiumoocyst detection.Journal of Clinical Microbioogy.27:12 1490-1495.

[7] Barer, M. R. and Wright, A .E. (1990). Cryptosporidium and water.Letters in Applied Microbiology 11(2): $271-277$.

[8] Betancourt, W.Q. and Rose, J.B. (2004). Drinking water treatment processes for removal of Cryptosporidium and Giardia. Veterinary Journal of Parasitology126: 219-234.

[9] Blackburn, B.L., Craun, G.F., Yoder, J.S., Hill, V., Calderon, R.L., Chen, N., Lee, S.H. Levy, D.A. and Beach, M.J. (2004.) Surveillance for waterborne-disease outbreaks associated with drinking water.United States, 2001-2002. MMWR Surveillance Summary53: 23-45.

[10] Borchardt, M.A. and Spencer, S.K. (2002). Concentration of Cryptosporidium, microsporidia and other water-borne pathogens by continuous separation channel centrifugation. Journal of Applied Microbiol92: 649-656.

[11] Bradford, S.A., and J.F. Schijven. (2002). Release of Cryptosporidium and Giardia from dairy calf manure: Impact of solution salinity. Environment Science Technology36:3916-3923.

[12] Bridgman, S.A., Robertson, R.M., Syed, Q., Speed, N. Andrews, N. and Hunter, P.R. (1995). Outbreak of Cryptosporidiosis associated with disinfected ground water. Epidemiology and Infection 155: 555 - 558.

[13] Barer, M. R. and Wright, A .E. (1990). Cryptosporidium and water.Letters in Applied Microbiology 11(2): $271-277$.

[14] Baxby, D., Hart. C. A. and Taylor, C. (1983). Human cryptosporidiosis: A possible case of hospital cross infection. (case report). British Medical Journal287: 1760-1761.

[15] Calderon, R.L. and Craun, G.F. (2006). Estimates of endemic waterborne risks from communityintervention studies.Journal of Water Health4:(2), 89-99.

[16] Carey, C.M., Lee, H. and Trevors, J.T. (2004). Biology, persistence and detection of Cryptosporidiumparvum and Cryptosporidiumhominisoocyst. Water Research 38: 818-862.

[17] Cartwright, R.Y. (2003). Food and waterborne infections associated with package holidays. Journal of AppliedMicrobiology94 : 12S-24S.

[18] Elizabeth, F. and Dwight, B. (2003). oocyst inactivation in field soil and its relation to soil characteristics: analyses using the geography information systems. Science of the total environment 321 (3): $472-581$.

[19] Fayer R, Morgan, U and Upton, S.J. (2000) Epidemiology of Cryptosporidium: transmission, detection and identification. International Journal for parasitology 30(12):12-13. 
[20] Gatei, W, Wamae, C.N, Mbae, C, et al.(2006) Cryptosporidiosis: prevalence, genotype analysis, and symptoms associated with infections in children in Kenya. America Journal of Tropical Medicine and Hygine75:78-82.

[21] Hunter, P.R. (2000). Advice on the response to reports from public and environmental health to the detection of cryptosporidialoocysts in treated drinking water.Community Disease and. Public Health3:2427.

[22] 39. Hayes, E.B., Matte, T.D., O’Brien T.R., Logsdo G.S., Rose, J.B., Ungar, B.L., Word, D.M., Pinsky, P.F., and Cummings, M.L.,(1989). Large community outbreak of Cryptosporidiosis due to contamination of a filtered public water supply.New England Journal of Medicine3921: 1372-1376.

[23] Henricksen, S. A. and pohlenz, J. F. L. (1981). Staining of Crytosporidia by a modified Ziehl-Neelsen technique. (short communication). ActaVeterinaricusScandinavica22: 594-596.

[24] Harp, J.A., fayer, R., B.A. and Jackson, G.J. (1996). Effect of pasteurization on inefectivity of oocysts in water and milk.Applied Environmental Microbiology 62: 2866-2868.

[25] Harrington, G., Chen, JH., Harris, A., Xagoraraki, I.I., Battigelli, D. and Standridge, J.(2002). Removal of emerging waterborne pathogens, AwwaRF and AWWA, Denver.

[26] LeChevallier, M.W., Norton, N.D., Lee, R.G., (1991). Occurrence of Giardia and Cryptosporidium spp. in surface water supplies.Applied Environmental Microbiology57:2610-2616

[27] Mata, L. (1986). Cryptosporidium and other protozoa in diarrhoea disease in less developed countries. Pediatric of Infection Diseases 5: 117 - 129.

[28] Madore, M. S., Rose, J. B., Gerba, C. R., Arrowood, M. J. and Sterling, C. R. (1987). Occurance of Cryptosporiddiumoocysts in sewage effluents and selected surface waters.Journal of parastitology73(4): 702-705.

[29] Njoku, O. M., Uneke C.J., Omalu, I.C.J., Inyama, P. U., Jagun, B. I., Duhlinska, D. D. (2005). Occurrence of Cryptosporidiumspeceies in surface water in the Jos, Plateau.Journal of Science in Agriculture, Food Technology and the Environment 5: 59- 62.

[30] Nichols,R.A, Grimason, A.M, Campbell, B.M, Tembo, K.C, Smith, H.V.(2007). Incidence of cryptosporidiosis species in paediatric patients in Malawi.Epidemiology and Infection35:1307-1315.

[31] Perch, M, Sodemann, M, Jakobsen, M.S, Valentiner-Branth, P, Steinsland, H, Fischer, T.K, Lopes, D.D, Aaby, P, Molbak ,K(2001). Seven years' experience with Cryptosporidium parvum in Guinea-Bissau, West Africa.Annals TroicalPaediatric21:313-318.

[32] Rose J.B., Darbin H. Garba CP, (1988a). Correlation of the protozoa Cryptosporidium and Giardia with water quality variable in a water shed. Water Science Technology 45:543-567.

[33] Rose, J.B., Kayed, D., Madore, M.S. (1988b). Methods for recovery of Giardia and Cryptosporidium from environmental waters and their comparative occurrence, in: Wallis PM Hommond BR, eds advances in Giardia research, Calgary University of Calgory press.123-156.

[34] SamieP.O. Bessong, C.L. Obi, J.E.A.D. Sevilleja, S. Stroup, E. Houpt and R.L.(2006).Cryptosporidium species: Preliminary descriptions of the prevalence and genotype distribution among school children and hospital patients in the Venda region, Limpopo Province, South Africa. Journal of Clinical Microbiology.3:123-145

[35] Smith, H. V., Girdwood, R.W.A., Peterson, W. J., Hardle, R., Green, L.A., Benton, C., Tulloch, W., Sharp, J.C.M. and Forbes, G. I. (1988). Water-borne outbreak of Cryptosporidiosis (Letter) Lancetii: 1484.

[36] Smith H.V., patterson, W.J., Hardie, R.,(1989a). Waterborn outbreak of Cryptosporidiosis causes by post treatment ion termination. Epidemology infection.Parasitology Today 6: 8-12.

[37] Storling C.R., Seegar, k., Sinclair, N.A. (1986).Cryptosporidium as a causative agent of travelers diarrhea. Journal infection.Disease.153: 380-381.

[38] Tzipori S. (1983). Cryptosporidiosis in animal and humans.Microbial Review 47: 84-96.

[39] Village, I.L. (2006).An outbreak of Cryptosporidium hominis infection at an Illinois recreational waterpark. Epidemiology Infectious134: 147-156.

[40] Xiao, L, Sing, A., Limor, J., Graczyk, T.K., Grains, S. Lala, .A. (2001). Moleculur characterization of Cryptosporidium oocysts in samples of raw surface water and waste water. Applied Environmental Microbiology 43: 55-59.

[41] Xiao, L., Tayer, R., Ryan V., and Upton S.J. (2004). Cryptosporidium taxonomy: recent advances and implications for public health Cclininical Microbiology Review 26:9-13. 